\title{
Chlorpyrifos degrading Pseudomonas stutzeri isolated from pesticide contaminated soil
}

Parichat Phumkhachorn*, Pongsak Rattanachaikunsopon

Department of Biological Science, Faculty of Science, Ubon Ratchathani University, Ubon Ratchathani, Thailand

\begin{abstract}
Received:
December 15, 2019

Accepted:

March 20, 2020

Published:

July 30, 2020

Abstract

Pesticides have been continuously used by farmers worldwide, including Thailand leading to their accumulation in agricultural soils. Bioremediation using microorganisms to degrade pesticides in soils has currently become of interest because it is considered to be cost effective and safe. The main objectives of this study were to isolate and characterize bacteria degrading chlorpyrifos, an organophosphate pesticide commonly used in Thailand. The characterization of the isolated bacteria included chlorpyrifos tolerance study. The most chlorpyrifos tolerant isolate was further subjected to the determination of a gene responsible for chlorpyrifos degradation and molecular identification. For the isolation of chlorpyrifos degrading bacteria from soils, M9 minimal medium supplemented with 100 ppm was used. Of all 6 isolated chlorpyrifos degrading bacteria, the most chlorpyrifos tolerant bacterial isolate was a gram negative bacterial isolate CHL3. It was tolerant to chlorpyrifos as high as 2,000 ppm. From plasmid isolation, it was found that the bacterial isolate CHL3 had no plasmid, indicating that a gene responsible for chlorpyrifos degradation was on the chromosome. When it was subjected to the $16 \mathrm{~S}$ rDNA sequence analysis, it was identified as Pseudomonas stutzeri. The bacterium obtained from this study might be useful for its application in bioremediation of agricultural soils contaminated with chlorpyrifos and organophosphate pesticides.
\end{abstract} parichatphumkhachorn@yahoo.com

Keywords: Chlorpyrifos, Organophosphates, Pesticides, Pseudomonas

\section{How to cite this:}

Phumkhachorn P and Rattanachaikunsopon P, 2020. Chlorpyrifos degrading Pseudomonas stutzeri isolated from pesticide contaminated soil. Asian J. Agric. Biol. 8(3): 268-273. DOI: https://doi.org/10.35495/ajab.2019.12.573

This is an Open Access article distributed under the terms of the Creative Commons Attribution 3.0 License. (https://creativecommons.org/licenses/by/3.0), which permits unrestricted use, distribution, and reproduction in any medium, provided the original work is properly cited.

\section{Introduction}

Modern day agriculture depends on advanced technologies to increase productivity to serve rapidly increasing global population. The use of chemicals including pesticides is the most common approach to upscale the production of agricultural products especially fruits and vegetables. However, the abuse of such chemicals has created adverse effects not only to environments but also to health of farmers (Aktar et al., 2009).

Pesticides are collective name for chemicals used to protect plants from several kinds of plant enemies such as weeds, insects and microorganisms. Therefore, herbicides, insecticides, bactericides, fungicides, nematicides and molluscicides are 
pesticides. Among them, herbicides are the most commonly used pesticides which account for approximately $80 \%$ of all pesticides use (Aktar et al., 2009).

Chlorpyrifos is one of the most highly used organophosphate insecticides. It is a yellow liquid with pungent odor. It is generally used in agriculture and gardening to control insect pests including aphids, mealy bugs, whiteflies, cutworms, ground beetles and caterpillars (Mie et al., 2018). It kills insects by inhibiting their acetylcholinesterase enzyme leading to excessive accumulation of the neurotransmitter acetylcholine and eventually to neuromuscular transmission impairment. When chlorpyrifos is applied to agricultural fields, it can spread everywhere in the environment including air, soil, underground water and water resources (such as canals and rivers) causing significant problems to ecosystems (Mackay et al., 2014; Mie et al., 2018). Although chlorpyrifos can pose environmental threat, it is still being used widely in many developed and developing countries.

Environmental concerns associated with the contamination of organophosphate insecticides including chlorpyrifos in the environment have urged scientists to find effective, safe and accessible remediation approaches for detoxification of environmentally contaminated organophosphate insecticides. Bioremediation is the method using organisms such as microorganisms and plants to degrade organophosphate insecticides to nontoxic derivatives. Several strains of microorganisms have been found to have such activity such as Bacillus circulans, Brevibacillus brevis, Bukholderia sp., Pseudomonas sp. and Staphylococcus sp. (Singh and Walker, 2006; Jariyal et al., 2018; Sutapak et al., 2018). The use of nanoparticles such as bimetallic $\mathrm{Fe} / \mathrm{Ni}$ nanoparticle for catalytic degradation of organophosphate insecticides has also been reported.

It is hypothesized that soils exposed to pesticides for a long time may contain some pesticide degrading bacteria beneficial for bioremediation. Therefore, this study aimed to isolate chlorpyrifos degrading bacteria from agricultural soil continuously exposed to organophosphates insecticides more than 10 years. The isolated bacteria were tested for their chlorpyrifos tolerance ability. The location of a gene responsible for chlorpyrifos degrading ability was also examined. Finally, the most chlorpyrifos tolerant bacterium was subjected to molecular identification. The chlorpyrifos degrading bacteria obtained from this study may be useful for bioremediation of chlorpyrifos and other organophosphate insecticides contaminated in the environment.

\section{Material and Methods}

\section{Isolation of chlorpyrifos degrading bacteria from agricultural soil}

The soil used in this study was collected from red chilli agricultural farms continuously exposed to organophosphate insecticides more than 10 years. Ten $\mathrm{g}$ of soil sample were added into $90 \mathrm{ml}$ of M9 minimal broth containing $100 \mathrm{ppm}$ of chlorpyrifos (M9Bp100). The soil suspension was incubated on a shaker $(150 \mathrm{rpm})$ at $37^{\circ} \mathrm{C}$ for $72 \mathrm{~h}$. The liquid part of the suspension was subjected to ten-fold serial dilution. The appropriate dilutions were plated onto M9 minimal agar containing $100 \mathrm{ppm}$ of chlorpyrifos (M9A-p100) and incubated at $37^{\circ} \mathrm{C}$ for $24 \mathrm{~h}$. Single colonies of bacteria grown on the agar were randomly selected and restreaked on the same agar for purification. Morphological characteristics of the purified bacteria were initially examined by Gram staining method. For further use, they were kept in M9B-p100 containing $20 \%$ glycerol at $-20^{\circ} \mathrm{C}$.

\section{Chlorpyrifos tolerance ability}

Chlorpyrifos tolerance ability of the isolated bacteria was examined by the broth dilution assay. A set of 2.4 $\mathrm{ml}$ of M9 minimal broth was prepared to contain different concentrations of chlorpyrifos $(125,250$, $500,1,000,1,500$ and 2,000 ppm). To each prepared broth, $0.1 \mathrm{ml}$ of $24 \mathrm{~h}$ culture of bacteria was added to obtain the final concentration of bacterial of $10^{3}$ $\mathrm{cfu} / \mathrm{ml}$. After incubation at $37^{\circ} \mathrm{C}$ for $48 \mathrm{~h}$, the bacterial growth was observed by comparing the turbidity of bacterial cultures having different chlorpyrifos concentrations with that of a control bacterial culture without chlorpyrifos.

\section{Plasmid isolation}

For Isolation of bacterial plasmid, the protocol described by Anderson and McKay (1983) was used. However, rather than using cultures grown at $32^{\circ} \mathrm{C}$ in M-17 broth as recommended in the protocol, cultures grown at $37^{\circ} \mathrm{C}$ in M9B-p100 were used for plasmid isolation in this study. For positive and negative controls, Escherichia coli with and without $5.3 \mathrm{~kb}$ plasmid pN014-GFP were used, respectively (Phumkhachorn et al., 2007). The plasmid isolation results were checked by agarose gel electrophoresis using $1 \%$ of agarose gel. 


\section{Bacterial identification}

The protocol of 16S rDNA sequence analysis described by Butprom et al. (2013) was used. The universal primers used in this study were fD1 (5'AGAGTTTGATCCTGGCTCAG3') and rP2 (5'ACGGCTACCTTGTTACGACTT3'). The 16S rDNA obtained from PCR was sequenced by BioDesign (Pathumthani, Thailand) and analyzed by the NCBI Blast program. The sequence of $16 \mathrm{~S}$ rDNA gene obtained from this study was submitted in GenBank database. It was also subjected to phylogenetic analysis comparing with other species belong to the family Enterobacteriaceae. Multiple sequence alignment was performed using ClustalW and phylogenetic tree was inferred using PhyML v20160115.

\section{Results}

Isolation of chlorpyrifos degrading bacteria from agricultural soil

The isolation of chlorpyrifos degrading bacteria from agricultural soil was performed on M9A-p100 agar. Six different appeared colonies were found to grow on the agar (Table 1). They were designated CHL1CHL6. After bacterial purification by restreaking, Gram staining was used to initially examine the morphology of the bacteria. All of the chlorpyrifos degrading bacteria appeared under the microscope with 1,000x magnification as Gram negative rod shaped bacteria.

Table-1: Colony morphology of isolated bacteria

\begin{tabular}{|c|l|}
\hline Isolated bacteria & \multicolumn{1}{c|}{ Colony morphology } \\
\hline CHL1 & White shinny colony with regular edge \\
\hline CHL2 & White shinny colony with irregular edge \\
\hline CHL3 & White colony with regular edge \\
\hline CHL4 & White colony with irregular edge \\
\hline CHL5 & White small colony with regular edge \\
\hline CHL6 & White small colony with irregular edge \\
\hline
\end{tabular}

\section{Chlorpyrifos tolerance ability}

When CHL1 to CHL6 were cultured in M9 broth with different chlorpyrifos concentrations $(125,250,500$, $1,000,1,500$ and 2,000 ppm), different growth ability of the bacteria was observed. Among them, CHL3 was the most tolerant bacteria to chlorpyrifos because it was the only bacterial isolate capable of growing in the M9 broth with 2,000 ppm of chlorpyrifos (Table 2).
Therefore, CHL3 was selected for further study.

Table-2: Chlorpyrifos tolerance of isolated bacteria

\begin{tabular}{|c|c|c|c|c|c|c|}
\hline \multirow{2}{*}{$\begin{array}{c}\text { Chlorpyrifos } \\
\text { (ppm) }\end{array}$} & \multicolumn{7}{|c|}{ Isolated bacteria } \\
\cline { 2 - 7 } & CHL1 & CHL2 & CHL3 & CHL4 & CHL5 & CHL6 \\
\hline 125 & + & + & + & + & + & + \\
\hline 250 & + & + & + & + & + & + \\
\hline 500 & + & + & + & + & - & + \\
\hline 1,000 & - & + & + & - & - & + \\
\hline 1,500 & - & - & + & - & - & + \\
\hline 2,000 & - & - & + & - & - & - \\
\hline
\end{tabular}

$+=$ can grow in the medium with chlorpyrifos;

- = cannot grow in the medium with chlorpyrifos

\section{Plasmid isolation of CHL3}

To examine whether CHL 3 carried a plasmid, plasmid isolation was performed. After analyzing the plasmid isolation product from CHL3 by agarose gel electrophoresis, no DNA band was found on $1 \%$ agarose gel (Fig. 1). From tis result, it was likely that CHL3 did not have any plasmid. This result was confirmed by the successful isolation of $5.3 \mathrm{~kb}$ plasmid pN014-GFP from E. coli that was used as a positive control (Fig. 1).

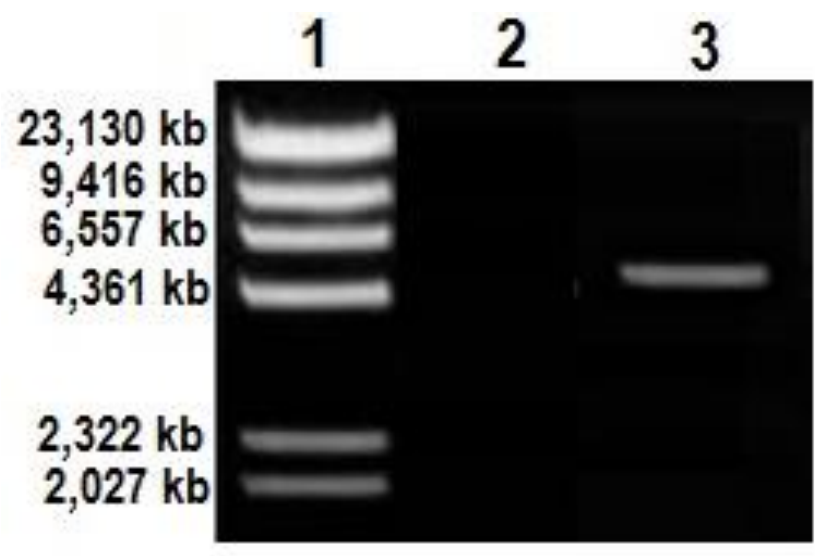

Figure-1: Agarose gel electrophoresis: Lane 1 = Lambda DNA digested with HindIII marker; Lane $\mathbf{2}=$ the absence of plasmid band from the plasmid isolation of CHL3; Lane $3=5.3 \mathrm{~kb}$ plasmid isolated from $E$. coli carrying pN014-GFP.

\section{Bacterial identification}

Molecular identification of CHL3 was performed by using 16S rDNA sequence analysis. The PCR amplification of $16 \mathrm{~S}$ rDNA of CHL3 resulted in a 1,496 bp amplicon. The sequence was submitted in GenBank database. Its accession number is MT138539. When the sequence was aligned to the known bacterial 16S rDNA sequences in GenBank 
database using NCBI Blast program, it showed 99\% similarity to $16 \mathrm{~S}$ rDNA sequence of Pseudomonas stutzeri ATCC 17588 (accession number NR_103934.2). Phylogenetic analysis based on $16 \mathrm{~S}$ rDNA sequences also showed that among bacterial species in the family Enterobacteriaceae, CHL3 was closely related to Pseudomonas stutzeri (Fig. 2). These results suggested that CHL3 was likely to be Pseudomonas stutzeri.

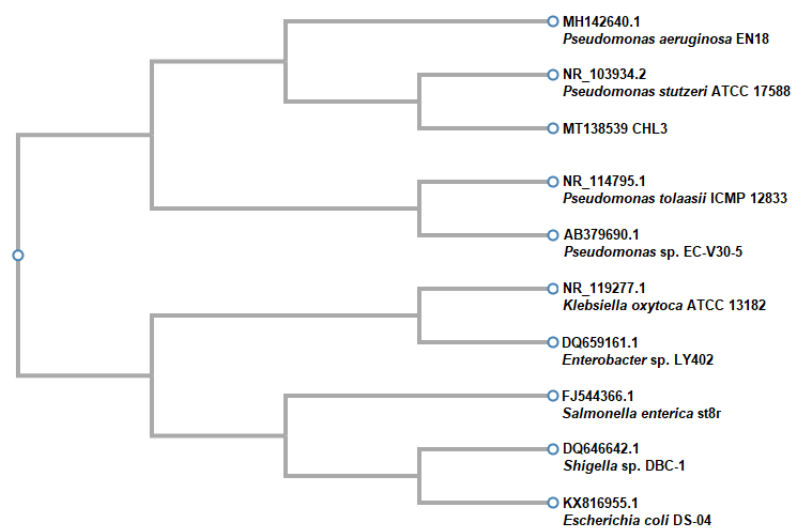

Figure-2: Phylogenetic tree based on 16S rDNA sequences, showing the relationship between CHL3 and other species belong to the family Enterobacteriaceae.

\section{Discussion}

In this study, agricultural soil samples exposed to organophosphate insecticides for more than 10 years were used as sources of chlorpyrifos digesting bacteria to increase chance to find the desired bacteria. Bacteria residing in such soil have to adjust themselves to be tolerant to the pesticides. Several mechanisms of pesticide tolerance have been used by bacteria including pumping pesticide out of cells by efflux pump (Silver and Phung, 1996), altering receptors to the forms that no longer bind to pesticides (McBride and Wolfe, 1971; Bentley and Chasteen, 2002) and digesting pesticides to nontoxic forms (Aguirre and Lowe, 2010(. The bacteria using the latter mechanism of pesticide tolerance were to be isolated in this study. To distinguish chlorpyrifos degrading bacteria from other bacteria, M9 minimal medium containing $100 \mathrm{mM}$ of chlorpyrifos was used as a selective medium. Since M9 minimal medium does not have carbon source for bacterial growth, bacteria that can grow on the selective medium have to digest chlorpyrifos to supply carbon source to promote bacterial growth. Other bacteria that cannot digest chlorpyrifos do not have carbon source for bacterial growth. Since the selective medium has chlorpyrifos as a carbon source, it is still very limited for supporting bacterial growth. This may be the reason for having only 6 bacterial colonies (CHL1CHL6) grown on the medium.

When all of chlorpyrifos digesting bacteria were tested for their tolerance to chlorpyrifos, it was found that CHL3 was the most chlorpyrifos tolerant strain. The actual explanation for this finding is still unknown. It is possible that CHL3 may produce more chlorpyrifos digesting enzyme than the other 5 bacterial strains or it may use more than one mechanisms of chlorpyrifos tolerance. To clarify this question, further study is required.

Several previous reports have shown that genes responsible for digestion of insecticides in bacteria can be found on plasmids or chromosome. Those found on plasmids were reported in Staphylococcus aureus (Umamaheswari and Murali 2010) Sphingomonas sp. (Feng et al., 1997) and Agrobacterium radiobacter (Horne et al., 2002) while those found on chromosome were reported in Agrobacterium radiobacter (Horne et al., 2002) and Arthrobacter sp. (Ohshiro et al., 1997). Therefore, it was of interest to examine where a gene responsible for digestion of chlorpyrifos of CHL3 was located. Since plasmid isolation revealed that CHL 3 contained no plasmid, it was likely that its gene was located on chromosome.

Molecular identification demonstrated that CHL3 was Pseudomonas stutzeri. Other bacteria in the genus Pseudomonas were also found to be able to digest chlorpyrifos; for examples, Pseudomonas aeruginosa (Bhatia and Malik, 2013), Pseudomonas putida (Gilani et al., 2016) and Pseudomonas spp. (Rayu et al., 2017). Besides Pseudomonas spp., several bacterial genera were also reported to have chlorpyrifos digesting ability including Achromobacter xylosoxidans (Akbar and Sultan, 2016), Bacillus sp. (Li et al., 2008), Brevundimonas sp. (Li et al., 2008), Ochrobactrum sp. (Akbar and Sultan, 2016), Paracoccus sp. (Fan et al., 2018), Sphingomonas sp. (Li et al., 2008), Stenotrophomonas sp. (Li et al., 2008) and Xanthomonas sp. (Rayu et al., 2017). 


\section{Conclusion}

The chlorpyrifos degrading bacteria obtained from this study was Pseudomonas stutzeri CHL3. It was highly tolerant to chlorpyrifos as high as 2,000 ppm compared to an average concentration of chlorpyrifos contaminated in the environment (50-100 ppm). In general, bacteria capable of digesting a specific organophosphate insecticide tend to digest other organophosphate insecticides because they have very similar core structure. Therefore, Pseudomonas stutzeri CHL3 has potential to be used for bioremediation not only chlorpyrifos but also other organophosphate insecticides contaminated in the environment.

\section{Disclaimer: None.}

Conflict of Interest: None.

Source of Funding: None.

\section{References}

Aguirre SP and Lowe KL, 2010. Pesticide-tolerant bacteria isolated from agricultural canals in the lower Rio Grande Valley of South Texas. Online J. Biol. Sci. 10(3): 126-135.

Anderson DG and McKay LL, 1983. Simple and rapid method for isolating large plasmid DNA from lactic streptococci. Appl. Environ. Microbiol. 46(3): 549-552.

Akbar S and Sultan S, 2016. Soil bacteria showing a potential of chlorpyrifos degradation and plant growth enhancement. Braz. J. Microbiol. 47(3): 563-570.

Aktar MW, Sengupta D and Chowdhury A, 2009. Impact of pesticides use in agriculture: their benefits and hazards. Interdiscip. Toxicol. 2(1): 112.

Bentley R and Chasteen TG, 2002. Microbial methylation of metalloids: Arsenic, antimony and bismuth. Microbiol. Mol. Biol. Rev. 66(2): 250271.

Bhatia D and Malik DK, 2013. Isolation and characterization of chlorpyrifos degrading soil bacteria of environmental and agronomic significance. J. Environ. Sci. Eng. 55(2): 227-238.

Butprom S, Phumkhachorn $P$ and Rattanachaikunsopon P, 2013. Effect of Lactobacillus plantarum $\mathrm{C} 014$ on innate immune response and disease resistance against
Aeromonas hydrophila in hybrid catfish. Sci. World J. 2013:1-6.

Fan S, Li K, Yan Y, Wang J, Wang J, Qiao C, Yang T, Jia Y and Zhao B, 2018. A novel chlorpyrifos hydrolase CPD from Paracoccus sp. TRP: Molecular cloning, characterization and catalytic mechanism. Electr. J. Biotechnol. 31(2018): 1016.

Feng X, Ou LT and Ogram A, 1997. Plasmidmediated mineralization of carbofuran by Sphingomonas sp. strain CF06. Appl. Environ. Microbiol. 63(4): 1332-1337.

Gilani RA, Rafique M, Rehman A, Munis MF, Rehman SU and Chaudhary HJ, 2016. Biodegradation of chlorpyrifos by bacterial genus Pseudomonas. J. Basic Microbiol. 56(2): 105119.

Horne I, Sutherland TD, Harcourt RL, Russel RJ and Oakeshott JG, 2002. Identification of an opd (organophosphate degradation) gene in an Agrobacterium isolate. Appl. Environ. Microbiol. 68(7): 3371-3376.

Jariyal M, Jindal V, Mandal K, Gupta VK and Singh B, 2018. Bioremediation of organophosphorus pesticide phorate in soil by microbial consortia. Ecotoxicol. Environ. Saf. 159: 310-316.

Li X, Jiang J, Gu L, Ali SW, He J and Li S, 2008. Diversity of chlorpyrifos-degrading bacteria isolated from chlorpyrifos-contaminated samples. Int. Biodeter. Biodegrad. 62(4): 331-335.

Mackay D, Giesy JP and Solomon KR, 2014. Fate in the environment and long-range atmospheric transport of the organophosphorus insecticide, chlorpyrifos and its oxon. Rev. Environ. Contam. Toxicol. 231: 35-76.

McBride BC and Wolfe RS, 1971. Biosynthesis of dimethylarsine by a methanobacterium. Biochemistry. 10(23): 4312-4317.

Mie A, Ruden C and Grandjean P, 2018. Safety of safety evaluation of pesticides: developmental neurotoxicity of chlorpyrifos and chlorpyrifosmethyl. Environ. Health. 17: 77.

Ohshiro K, Ono T, Hoshino T and Uchiyama T, 1997. Characterization of isofenphos hydrolases from Arthrobacter sp. strain B-5. J. Ferment. Bioeng. 83(3): 238-245.

Phumkhachorn P, Rattanachaikunsopon $\mathrm{P}$ and Khunsook S, 2007. The use of $g f p$ gene in monitoring bacteriocin-producing Lactobacillus plantarum N014, a potential starter culture in nham fermentation. J. Food Prot. 70(2): 419-424. 
Rayu S, Nielsen UN, Nazaries L and Singh BK, 2017. Isolation and molecular characterization of novel chlorpyrifos and 3,5,6-trichloro-2-pyridinoldegrading bacteria from sugarcane farm soils. Front. Microbiol. 8: 518.

Silver S and Phung LT, 1996. Bacterial heavy metal resistance: new surprises. Ann. Rev. Microbiol. 50: 753-789.

Singh BK and Walker A, 2006. Microbial degradation of organophosphorus compounds. FEMS Microbiol. Rev. 30(3): 428-471.

Sutapak T, Phumkhachorn P and Rattanachaikunsopon P, 2018. Characterization of profenofos tolerant bacteria isolated from pesticide contaminated soil. J. Sci. Technol. Ubon Ratchathani Uni. 20(3): 173-179.

Umamaheswari S and Murali M, 2010. Prevalence of plasmid mediated pesticide resistant bacterial assemblages in crop fields. J. Environ. Biol. 31(6): 957-964.

\section{Contribution of Authors}

Phumkhachorn P: Conceived idea, conducted research, collected and analysed data and wrote manuscript

Rattanachaikunsopon P: Helped in data collection, analysis and article write up 